\title{
Novel Approaches in Pilonidal Sinus Treatment
}

\author{
Arda Isik', Oguz Idiz ${ }^{2}$, Deniz Firat ${ }^{3}$ \\ ${ }^{1}$ Department of General Surgery, School of Medicine, Erzincan University, \\ Erzincan, Turkey; \\ ${ }^{2}$ Department of General Surgery, Sisli Etfal Training and Research Hospital, \\ Istanbul, Turkey; \\ ${ }^{3}$ Department of General Surgery, Sevket Yılmaz Training and Research Hospital, \\ Bursa, Turkey \\ Received June 14, 2016; Accepted November 14, 2016.
}

Key words: Pilonidal sinus - Treatment - Surgery - Recurrence

\begin{abstract}
Pilonidal sinus is a very common inflammatory disease of the gluteal region. The ideal method of pilonidal sinus treatment should have a low recurrence rate with minimum excision. Moreover, the treatment method should have a short hospitalization time, should let the patient return to his normal life rapidly, should cause minimum loss of labour and should result a small scar only. In the presented review, modalities in pilonidal sinus treatment in the light of current information in the literature are evaluated.
\end{abstract}

Mailing Address: Arda Isik, MD., Department of General Surgery, School of Medicine, Erzincan University, Erzincan, Turkey; Phone: +90 53305807 07; e-mail:kararda@yahoo.com 


\section{Introduction}

Pilonidal sinus is a very common inflammatory disease of gluteal region (McCallum et al., 2008). Its incidence is $26 / 100,000$ and it usually occurs in working males of age 15 to 30 (Søndenaa et al., 1995a; McCallum et al., 2008; Farrell and Murphy, 2011). In the literature, a wide range of factors is defined in its etiology. Keratin plugs, foreign substance reaction related to hairs and occurrence of dermopathy and debris in the hair follicles in the natal cleft are the factors most frequently held responsible (Page, 1969; von Laffert et al., 2011; Meinero et al., 2014). Pilonidal sinus disease and its treatment cause discomfort, limitation of mobility and deterioration of the quality of life of the patient (Marsh, 2008; Stewart et al., 2008). Despite the presence of several procedures defined in the treatment of chronic and recurrent pilonidal sinus disease, there isn't a standard view on which method is the best one. Recurrence rates of complex pilonidal sinus following surgical treatment vary between 0-46\% (Shafik, 1996). The ideal method of pilonidal sinus treatment should have a low recurrence rate with minimum excision. Moreover, the exemplary treatment method should have short hospitalization time, should let the patient to return to his normal life rapidly, should cause minimum loss of labour and should result in a minimal scar (Bayhan et al., 2016). In this review, we aimed to evaluate the modalities in pilonidal sinus treatment in light of the current information in the literature.

\section{Treatment options}

Although pilonidal sinus abscess treatment is usually applied under local anaesthesia, excision often requires loco-regional or general anaesthesia (Isgör, 2011). The patients often lay in the prone position and sacrococcygeal protrusion up and the hips are separated from each other by the help of plasters. Drainage and antibiotic therapy usage are required after local anaesthesia in patients with abscess development in acute period. It is reported that prophylactic antibiotic usage in post-excision period doesn't reduce complications and recurrence; it doesn't accelerate healing and doesn't avoid lesion infections (Søndenaa et al., 1995b).

\section{Conservative techniques}

There are several methods published in the literature about surgical treatment of pilonidal sinus. The most frequently used are: primary closure, lay open, and the flap plasty techniques.

\section{Lay open}

Lay open method can include the resection of the sinus whether by a wide range excision of cavity and sinus or only resection of the sinus with a minimal incision, also the removal of the hairs and curettage of the cavity. The cavity occurring during a wide excision is formed so as to deepen toward the central position. 
In the minimal lay open method, the healing is much faster, and hospitalization duration is shorter than wide excision (Gupta, 2005; Mohamed et al., 2005; Hosseini et al., 2006; Rao et al., 2010; Lorant et al., 2011). In a review analysing the studies performed with laying open and curettage techniques, a meta-analysis of 13 studies and 1,445 patients was made. In this study, the total recurrence rate was detected as $4.47 \%$, complication rate as $1.44 \%$, the length of operation time as 34.59 minutes and time of return to work as 8.4 days (Garg et al., 2016).

No matter the type of the excision, wide or minimal, the wound is left for secondary healing at the end. In such circumstances, the wound should be dressed daily, and infection development should be avoided (de Parades et al., 2013). With the marsupialization technique in which the edges of the wound are sutured, the injury is minimized, and this fastens the healing process (Mentes et al., 2004a). In recent years, various dressings and negative pressure wound care products are preferred (de Parades et al., 2013).

In a review published by McCallum et al. (2008), it is reported that the patients who are left for secondary healing following pilonidal sinus excision have a shorter hospitalization period and less recurrence development rate concerning the patients who undergo primary closure. However, there isn't a significant difference regarding wound infection. Moreover, wound healing time is much longer in patients left for secondary healing, and this negatively affects the quality of life.

\section{Primary suture}

While it is easy to close the wound in the middle line after the pilonidal sinus cavity and tracks are extracted, it also brings the problems such as the tension of the sutures and increase of this tension with movements. In the literature, recurrence rates following primary closure vary in a wide range of $0-42 \%$. While recurrence rate following primary closure is found as $18.4 \%$ in the study of Can et al. (2009), this rate is reported as $4.3 \%$ by Toccaceli et al. (2008) and $4 \%$ by Muzi et al. (2009) (lesalnieks et al., 2003).

\section{Bascom technique}

In Bascom technique, hair follicles in midline gluteal region are excised with incisions of 2-4 mm and then an incision is made in lateral a few centimetres parallel to the midline and a subcutaneous tunnel is opened towards the midline and the hair and granulation tissue is cleaned away. The wound isn't sutured. Bascom (1983) has reported that the average healing time of the patients in his series followed-up during 3.5 years is three weeks, and the recurrence rate is $16 \%$.

\section{Karydakis technique}

Karydakis has indicated that suture line formed in midline will produce a serious tension following strong gluteal muscle spasms, and for this reason, the midline should be shifted. With the method he developed, after excision of the pilonidal 
sinus tissue with a unilateral elliptical incision, he forms a deep flap in the contralateral side including subcutaneous tissue and then sutures this flap to the sacral fascia, and makes the primary closure of the skin on the lateral of the midline. In the 2-20 years of follow-up of 7,471 patients that he has operated with this technique, the recurrence rate is reported as 0-1\% (Karydakis, 1992; de Parades et al., 2013).

\section{Plasties}

These methods have a broad range of variety and they are developed with indications related to plastic surgery and are used for the purpose of wound closure following pilonidal sinus surgery. Today the most common plasty methods are Limberg flap, $\mathrm{V}-\mathrm{Y}$ plasty, and $\mathrm{Z}$ plasty. In the literature, wound infection, wound separation and seroma rates after $\mathrm{V}-\mathrm{Y}$ plasty are reported respectively as: $0-10.2 \%$, 0-10.2\% and 0-4.6\% (Schoeller et al., 1997; Milito et al., 1998; Nursal et al., 2010). In a study including 353 cases operated with Limberg flap, the recurrence rate is reported as $3.1 \%$, and infection rate as 6.5\% (Mentes et al., 2008). In another study made with modified Limberg flap the recurrence rate is indicated as $1.2 \%$ (Mentes et al., 2004b). Lee et al. (2008) defend the idea that primary closure can be used in the primary disease, but flap must be used in recurrent disease. Also, Lieto et al. (2010) have used the flap reconstruction technique in 55 recurrent pilonidal patient series and only one patient (1.8\%) presented recurrence. In a retrospective study of 55 patients comparing fasciocutaneous V-Y advancement flap (VYF) and Limberg transposition flap (LTF) techniques for recurrent pilonidal sinus disease, it is shown that for the patients who underwent Limberg transposition flap, the duration of the operation is shorter. And also the volume extracted is smaller, the length of hospital stay is shorter and patients return to work earlier in LTF group compared to VYF group (Öz et al., 2015). In the case of repair of the defect with a flap in pilonidal sinus patients, instead of a $V-Y$ flap, the first choice should be Limberg flap due to recurrence and shorter hospitalization time.

\section{Minimal invasive therapies}

Due to the advantages such as earlier discharge from the hospital, quicker return to work, minimally invasive techniques are being used more frequently by the patients and surgeons instead of wide excisions.

Endoscopic pilonidal sinus surgery is a new invasive treatment procedure in pilonidal sinus treatment. In this technique, pilonidal sinus, pilonidal fistula tract are extracted endoscopically, hair follicles and keratin debris are destructed (Meinero et al., 2016). In a study made by Meinero and Mori (2011), 11 pilonidal sinus patients are treated by video-endoscopic technique. The patients are discharged on the same day, and no recurrence is detected during six months follow-up. In another prospective endoscopic pilonidal sinus study of 250 patients operation was performed in two phases as diagnosis and surgery phase, while total wound healing 
time is reported as $26.7 \pm 10.4$ days, total wound healing rate is $94.8 \%$. In $5.2 \%$ of patients without wound healing, the external exotoxin quantity was statistically higher. No significant difference was found between the failure rates following the usage of endoscopic treatment as the primary treatment and the failure rates following the usage of endoscopic treatment after another treatment that failed. The average time of return to work was reported as $2 \pm 0.5$ days after the operation and recurrence developed in 12 (5\%) patients during the follow-up period of 12 months (Meinero et al., 2016). In a study comparing the modified Limberg flap reconstruction $(n=44)$ and crystallized phenol application $(n=37)$, no significant difference is seen regarding recurrence and hematoma and wound infection development rates during average 16.5 months follow-up (Bayhan et al., 2016).

Fibrin glue which is another minimally invasive treatment method in pilonidal sinus surgery is also used in different treatment techniques. Filling of the sinus tract with fibrin glue is a new method that can be used instead of surgery. Moreover, fibrin glue can be used as a concealer on the wound surface left open after the surgery or to fill the dead space that occurs after primary closure. In four studies in the literature, fibrin glue was used in 113 patients after pilonidal sinus tracts were curetted and cleaned away (Lund and Leveson, 2005; Elsey and Lund, 2013; Isik et al., 2014; Smith et al., 2015). The success rate of these studies is reported as $80 \%$ in their meta-analysis. However, there isn't any information about the re-usage of fibrin glue in the patients who failed in these studies. Although similar studies were made for phenol and their success rates were found as $70 \%$, this rate increased to $86.7 \%$ in repeating implementations (Kayaalp et al., 2010; Olmez et al., 2013). The high cost of the fibrin glue on phenol is another disadvantage.

\section{Negative pressure wound therapy}

In recent years, negative pressure wound care products are one of the adjuvant therapy options that are thought to be useful both for open and closed wounds. Negative pressure wound care products absorb the liquid and exudate accumulated in the wound; reduce the number of bacteria and tissue edema. Moreover, negative pressure-induced tissue deformity activates some intracellular pathways that accelerate wound healing (Farrell and Murphy, 2011). Negative pressure wound care products are also associated with an increase in factors accelerating wound healing such as: wound oxygenation, angiogenesis, and blood flow, granulation tissue formation (EWMA, 2008). Relative contraindications of the negative pressure wound care products are necrotic tissue formation with eschar on in the wound, priority of debridement requirement, presence of an untreated osteomyelitis around the wound, cancer in the wound or development of a fistula towards an organ or body cavity (Cooper and Young, 2000; Eryilmaz et al., 2015). When VAC (vacuum-assisted closure) treatment used as negative pressure wound care product is compared with standard gauze dressings, it is reported that VAC treatment further reduces the depth of chronic wounds, provides a faster recovery, causes fewer infections 
and allows shorter hospitalization (Joseph et al., 2000; Vuerstaek et al., 2006; Mouës et al., 2007). But despite these advantages, each dressing change is subject to high costs.

\section{Conclusion}

Although pilonidal sinus disease is frequently observed, no standard treatment approach has been determined. In determining of the treatment method, the preferency of the surgeon, patient's request and extend of the disease are effective factors. Each method has a certain recurrence rate, and none of them is used as the gold standard. Although minimal treatment approaches are used more frequently in recent years, much more experience is needed.

\section{References}

Bascom, J. (1983) Pilonidal disease: long-term results of follicle removal. Dis. Colon Rectum 26, 800-807.

Bayhan, Z., Zeren, S., Duzgun, S. A., Ucar, B. I., Alparslan Yumun, H. N., Mestan, M. (2016) Crystallized phenol application and modified Limberg flap procedure in treatment of pilonidal sinus disease:A comparative retrospective study. Asian J. Surg. 39, 172-177.

Can, M. F., Sevinc, M. M., Yilmaz, M. (2009) Comparison of Karydakis flap reconstruction versus primary midline closure in sacrococcygeal pilonidal disease: results of 200 military service members. Surg. Today 39, 580-586.

Cooper, S. M., Young, E. (2000) Topical negative pressure. Int. J. Dermatol. 39, 892-896.

de Parades, V., Bouchard, D., Janier, M., Berger, A. (2013) Pilonidal sinus disease. J. Visc. Surg. 150, $237-247$.

Elsey, E., Lund, J. N. (2013) Fibrin glue in the treatment for pilonidal sinus: high patient satisfaction and rapid return to normal activities. Tech. Coloproctol. 17, 101-104.

Eryilmaz, R., Isik, A., Okan, I., Bilecik, T., Yekeler, E., Sahin, M. (2015) Does sacrococcygeal angle play a role on pilonidal sinus etiology? Prague Med. Rep. 116, 219-224.

European Wound Management Association (EWMA) (2008) Position Document: Negative Pressure Wound Therapy in Wound Management. MEP Ltd., London.

Farrell, D., Murphy, S. (2011) Negative pressure wound therapy for recurrent pilonidal disease: a review of the literature. J. Wound Ostomy Continence Nurs. 38, 373-378.

Garg, P., Menon, G. R., Gupta, V. (2016) Laying open (deroofing) and curettage of sinus as treatment of pilonidal disease: a systematic review and meta-analysis. ANZ J. Surg. 86, 27-33.

Gupta, P. J. (2005) Comparative study between radiofrequency sinus excision and open excision in sacrococcygeal pilonidal sinus disease. Dig. Surg. 22, 459-463.

Hosseini, S. V., Bananzadeh, A. M., Rivaz, M., Sabet, B., Mosallae, M., Pourahmad, S., Yarmohammadi, H. (2006) The comparison between drainage, delayed excision and primary closure with excision and secondary healing in management of pilonidal abscess. Int. J. Surg. 4, 228-231.

lesalnieks, I., Fürst, A., Rentsch, M., Jauch, K.W. (2003) Primary midline closure after excision of a pilonidal sinus is associated with a high recurrence rate. Chirurg 74, 461-468. (in German)

Isgör, A. (2011) Pilonidal hastalık. ANKEM Derg. 25, 117-120.

Isik, A., Eryılmaz, R., Okan, I., Dasiran, F., Firat, D., Idiz, O., Sahin, M. (2014) The use of fibrin glue without surgery in the treatment of pilonidal sinus disease. Int. J. Clin. Exp. Med. 7, 1047-1051.

Joseph, J., Hamori, C. A., Bergman, S., Roaf, E., Swann, N. F., Anastasi, G.W. (2000) A prospective, randomized trial of vacuum-assisted closure versus standard therapy of chronic nonhealing wounds. Wounds $\mathbf{1 2}$, 60-67.

Isik A.; Idiz O.; Firat D. 
Karydakis, G. E. (1992) Easy and successful treatment of pilonidal sinus after explanation of its causative process. Aust. N. Z. J. Surg. 62, 385-389.

Kayaalp, C., Olmez, A., Aydin, C., Piskin, T., Kahraman, L. (2010) Investigation of a one-time phenol application for pilonidal disease. Med. Princ. Pract. 19, 212-215.

Lee, P. J., Raniga, S., Biyani, D. K., Watson, A. J., Faragher, I. G., Frizelle, F. A. (2008) Sacrococcygeal pilonidal disease. Colorectal Dis. 10, 639-650.

Lieto, E., Castellano, P., Pinto, M., Zamboli, A., Pignatelli, C., Galizia, G. (2010) Dufourmentel rhomboid flap in the radical treatment of primary and recurrent sacrococcygeal pilonidal disease. Dis. Colon Rectum $\mathbf{5 3}$, 1061-1068.

Lorant, T., Ribbe, I., Mahteme, H., Gustafsson, U. M., Graf,W. (2011) Sinus excision and primary closure versus laying open in pilonidal disease: a prospective randomized trial. Dis. Colon Rectum 54, 300-305.

Lund, J. N., Leveson, S. H. (2005) Fibrin glue in the treatment of pilonidal sinus: results of a pilot study. Dis. Colon Rectum 48, 1094-1096.

Marsh, A. (2008) Caring for patients with pilonidal sinus disease. Nurs. Stand. 22, 59.

McCallum, I. J., King, P. M., Bruce, J. (2008) Healing by primary closure versus open healing after surgery for pilonidal sinus: systematic review and meta-analysis. BMJ 336, 868-871.

Meinero, P., Mori, L. (2011) Video-assisted anal fistula treatment (VAAFT): a novel sphincter-saving procedure for treating complex anal fistulas. Tech. Coloproctol. 15, 417-422.

Meinero, P., Mori, L., Gasloli, G. (2014) Endoscopic pilonidal sinus treatment (E.P.Si.T.). Tech. Coloproctol. 18, 389-392.

Meinero, P., Stazi, A., Carbone, A., Fasolini, F., Regusci, L., La Torre, M. (2016) Endoscopic pilonidal sinus treatment: a prospective multicentre trial. Colorectal Dis. 18, O164-O170.

Mentes, O. M., Ozdemir, M., Ozgul, O. (2004a) Pilonidal sinüs hastalığı ve cerrahi tedavisi. DIRIM 5, 48-53.

Mentes, B. B., Leventoglu, S., Cihan, A., Tatlicioglu, E., Akin, M., Oguz, M. (2004b) Modified Limberg transposition flap for sacrococcygeal pilonidal sinus. Surg. Today 34, 419-423.

Mentes, O., Bagci, M., Bilgin, T., Ozgul, O., Ozdemir, M. (2008) Limberg flap procedure for pilonidal sinus disease; results of 353 patients. Langenbecks Arch. Surg. 393, 185-189.

Milito, G., Cortese, F., Casciani, C. U. (1998) Rhomboid flap procedure for pilonidal sinus: results from 67 cases. Int. J. Colorectal Dis. 13, 113-115.

Mohamed, H. A., Kadry, I., Adly, S. (2005) Comparison between three therapeutic modalities for noncomplicated pilonidal sinus disease. Surgeon 3, 73-77.

Mouës, C. M., van den Bemd, G. J., Heule, F., Hovius, S. E. (2007) Comparing conventional gauze therapy to vacuum-assisted closure wound therapy: a prospective randomised trial. J. Plast. Reconstr. Aesthet. Surg. 60, 672-681.

Muzi, M. G., Milito, G., Nigro, C., Cadeddu, F., Farinon, A. M. (2009) A modification of primary closure for the treatment of pilonidal disease in day-care setting. Colorectal Dis. 11, 84-88.

Nursal, T. Z., Ezer, A., Caliskan, K., Törer, N., Belli, S., Moray, G. (2010) Prospective randomized controlled trial comparing V-Y advancement flap with primary suture methods in pilonidal disease. Am. J. Surg. 199, 170-177.

Olmez, A., Kayaalp, C., Aydin, C. (2013) Treatment of pilonidal disease by combination of pit excision and phenol application. Tech. Coloproctol. 17, 201-206.

Öz, B., Akcan, A., Emek, E., Akyüz, M., Sözüer, E., Akyldız, H., Aydın, H. (2015) A comparison of surgical outcome of fasciocutaneous $\mathrm{V}$ - $Y$ advancement flap and Limberg transposition flap for recurrent sacrococcygeal pilonidal sinus disease. Asian J. Surg. (Epub ahead of print)

Page, B. H. (1969) The entry of hair into a pilonidal sinus. Br. J. Surg. 56, 32.

Rao, M. M., Zawislak, W., Kennedy, R., Gilliland, R. (2010) A prospective randomised study comparing two 
treatment modalities for chronic pilonidal sinus with a 5-year follow-up. Int. J. Colorectal Dis. 25, 395-400.

Schoeller, T., Wechselberger, G., Otto, A., Papp, C. (1997) Definite surgical treatment of complicated recurrent pilonidal disease with a modified fasciocutaneous $V-Y$ advancement flap. Surgery 121, 258-263.

Shafik, A. (1996) Electrocauterization in the treatment of pilonidal sinus. Int. Surg. 81, 83-84.

Smith, C. M., Jones, A., Dass, D., Murthi, G., Lindley, R. (2015) Early experience of the use of fibrin sealant in the management of children with pilonidal sinus disease. J. Pediatr. Surg. 50, 320-322.

Søndenaa, K., Nesvik, I., Gullaksen, F., Furnes, A., Harbo, S. O., Weyessa, S., Søreide, J. A. (1995a) The role of cefoxitin prophylaxis in chronic pilonidal sinus treated with excision and primary suture. J. Am. Coll. Surg. 180, 157-160.

Søndenaa, K., Andersen, E., Nesvik, I., Søreide, J. A. (1995b) Patient characteristics and symptoms in chronic pilonidal sinus disease. Int. J. Colorectal Dis. 10, 39-42.

Stewart, A., Donoghue, J., Mitten-Lewis, S. (2008) Pilonidal sinus: healing rates, pain and embarrassment levels. J. Wound Care 17, 468-470.

Toccaceli, S., Persico Stella, L., Diana, M., Dandolo, R., Negro, P. (2008) Treatment of pilonidal sinus with primary closure. A twenty-year experience. Chir. Ital. 60, 433-438.

von Laffert, M., Stadie, V., Ulrich, J., Marsch, W. C., Wohlrab, J. (2011) Morphology of pilonidal sinus disease: some evidence of its being a unilocalized type of hidradenitis suppurativa. Dermatology 223, 349-355.

Vuerstaek, J. D., Vainas, T., Wuite, J., Nelemans, P., Neumann, M. H., Veraart, J. C. (2006) State-of-the-art treatment of chronic leg ulcers: a randomised controlled trial comparing vacuum-assisted closure (V.A.C.) with modern wound dressings. J. Vasc. Surg. 44, 1029-1037. 